\title{
BLOOD LACTATE CONCENTRATION FOLLOWING MAXIMUM EXERCISE IN TRAINED SUBJECTS
}

\author{
G. C. GASS, PhD, ${ }^{*}$ S. ROGERS, DipPhty, ${ }^{*}$ and R. MITCHELL, MSct \\ "Senior Lecturer, Department of Biological Sciences, Cumberland College of Health Sciences, Sydney, Australia \\ ** Lecturer, School of Physiotherapy, Western Australian Institute of Technology, Perth, Australia \\ tStatistician, Department of Behavioural and General Studies, Cumberland College of Health Sciences, \\ Sydney, Australia
}

\begin{abstract}
The time when blood lactate reaches peak concentration following maximum exercise is unclear. The post exercise venous blood lactate concentration was determined serially for $\mathbf{3 0}$ minutes in 13 trained men following maximum exercise on a motor driven treadmill. Lactates were determined enzymatically in duplicate. The $\mathrm{VO}_{2}$ max and percent

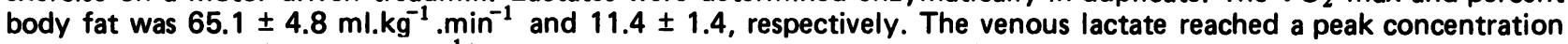
at the 6th minute $\left(14.2 \mathrm{mmol} . \mathrm{L}^{-1}\right)$ of an inactive recovery, and declined linearly thereafter to reach a concentration of $7.43 \pm 0.60 \mathrm{mmol} . \mathrm{L}^{-1}$ at the 30 th minute. The net rate of lactate removal was $.30 \mathrm{mmol} . \mathrm{L}^{-1}$. $\mathrm{min}^{-1}$. Statistical analysis found no significant difference in lactate concentration during the 4th, 5th and 6th minute post exercise, indicating that these post exercise times may be appropriate to sample venous blood for peak lactate concentration.
\end{abstract}

Index terms: post exercise, lactate, $\mathrm{VO}_{2} \max$

\section{INTRODUCTION}

Venous blood lactate concentration has long been considered a useful measurement in quantifying the extent of anaerobic metabolism during exercise and may be used as an objective criterion of the degree of exhaustion, (Åstrand et al, 1963). The extent to which venous blood lactate reflects the muscle lactate production is unclear, (Graham, 1978). Previous evidence indicated that muscle lactate was transported to the liver, converted to glucose and transported to the muscle for conversion into glycogen (Krebs, 1964; Krebs \& Woodford, 1965; Opie \& Newsholme, 1967). Contrary to this view are the experiments of Hermansen and Vaage (1978) and Hill (1924) indicating that substantial amounts of muscle lactate may be converted to glycogen in the muscle and that a further variable percent may be oxidised, (Keul et al, 1969).

In addition to the problems arising from the variable fates of muscle lactate, numerous investigations have assumed various times post exercise as appropriate to measure peak venous blood lactate concentrations following maximum exercise. These investigations have assumed, by their method of sampling, that peak venous lactate concentration may occur at varying times post exercise. These varying post exercise times include

\section{*Present Address:}

G. C. GASS, PhD

Cumberland College of Health Sciences, PO Box 170, Lidcombe, NSW 2141

Australia immediately (Asmussen, 1949), within the first minute, (McGrail et al, 1978), approximately $2 \mathrm{~min}$, (Hermansen and Stensvold, 1972; Knuttgen, 1962) 5 min (Johnson and Edwards, 1937), 6 min (Margaria et al, 1933), between 1 and $5 \mathrm{~min}$ (Hermansen and Vaage, 1977), 2 and 5 min (Freund and Gendry, 1978) 3 and 5 min (Margaria et al, 1969), 3 to 6 min (Davies et al, 1970), $3 \mathrm{~min}$ intervals (Karlsson et al, 1968) and $10 \mathrm{~min}$ or greater (Diament et al, 1968).

In view of the conflicting opinions as to when peak venous blood lactate concentration may occur, and the possible usefulness of venous blood lactate concentration as an index of exhaustion, an investigation was conducted to determine the most appropriate time to sample venous blood to determine peak venous blood lactate concentration.

\section{METHODS}

Thirteen healthy trained men whose mean age was $25.8 \pm 3.4$ years participated in the study. Each subject was required to make two visits to the laboratory. On the first occasion the subjects underwent a medical examination and were familiarised with the head gear, mouth piece and sundry equipment as well as learning to run on a motor driven treadmill. During the second visit the subjects were weighed to the nearest $0.1 \mathrm{~kg}$, wearing only shorts. Percent body fat and other anthropometric measurements were determined in accordance with the procedures in the National Exercise and Heart Disease project - Manual of Operations (1974). 
Maximum oxygen consumption was determined by having the subject run on a motor driven treadmill at $200 \mathrm{~m} \cdot \mathrm{min}^{-1}$ with a $2 \%$ increase in grade every minute, until the subject could continue no longer. Subjects breathed through a Hans Rudolph Valve (\#2700) and expired air was passed through an ice-cooled mixing chamber before passing through a Tissot calibrated Parkinson Cowan dry gas meter (CD4).

Expired air temperatures were recorded from a calibrated thermister in the expired air flow. Paramagnetic oxygen and infra-red carbon dioxide analysers continuously sampled expired air from an ice-cooled mixing chamber. Each analyser was calibrated frequently with mixtures of chemically analysed gas. Calculations were made each minute throughout the treadmill test of oxygen consumption $\left(\mathrm{VO}_{2} \mathrm{~L}\right.$. $\mathrm{min}^{-1}$, $\mathrm{ml} . \mathrm{kg}^{-1} \mathrm{~min}^{-1}$ ) ventilation corrected to STPD ( $V_{E}$ L. $\min ^{-1}$ ) and respiratory exchange ratio (R) using a PDP $11 / 10$ analogue computer. Heart rates were monitored continuously from a V5 lead and recorded pre-exercise, during the last $10 \mathrm{~s}$ of each minute of exercise, and for $5 \mathrm{~min}$ post exercise.

Immediately upon cessation of exercise the subject was assisted from the treadmill to a nearby couch and placed in the supine position with the feet slightly elevated. The venepuncture site was cleansed with alcohol and a 21 gauge INTRAVEN cannula was inserted into a antecubital vein, usually within $30-35 \mathrm{~s}$ after cessation of exercise.

Approximately $2 \mathrm{ml}$ of venous blood were sampled every minute for the first ten minutes, and thereafter every $5 \mathrm{~min}$ until $\mathbf{3 0} \mathrm{min}$ had lapsed from the cessation of exercise.

After the first sample of venous blood had been withdrawn, the cannula was flushed with heparinised saline $\left(5.0 \mathrm{IU} . \mathrm{m}^{1}\right)$ and $15 \mathrm{~s}$ prior to the subsequent sampling times approximately $0.5 \mathrm{ml}$ of venous blood was withdrawn and discarded. A sterile syringe was attached to the cannula, and at the time of sampling approximately 1.5 to $2 \mathrm{ml}$ of venous blood was withdrawn and placed in a tube containing sodium fluoride and potassium oxalate (venoject VT $050 \mathrm{FX}$ ). The tube was gently inverted several times and exactly $1.0 \mathrm{ml}$ of the venous blood was pipetted into a $10 \%$ perchloric acid solution, shaken vigorously and frozen. Duplicate blood lactates were analysed enzymatically (Calbiochem - Behring Corp.).

Means and standard deviations were calculated for all variables. An analysis of variance with repeated measures was used to test for significant differences in post exercise blood lactate concentration from the 1st to 30th min. A Newman-Keuls post-hoc test was administered when significant $F$ ratios were found. A $P$ value equal to or less than 0.05 was accepted as significant.

\section{RESULTS}

The anthropometric characteristics of the subjects and physiological data from the maximum treadmill test are presented in Table 1. The percent body fat estimated from the sum of three skinfolds (triceps, subscapular and suprailiac) was $11.4 \pm 1.4$. The relatively low percent body fat in the present group was associated with a high maximum oxygen consumption (65.1 \pm 4.8 $\left.\mathrm{ml} \cdot \mathrm{kg}^{-1} \cdot \mathrm{min}^{-1}\right)$. A continuous and incremental treadmill protocol produced a mean run time of $487 \pm 58 \mathrm{~s}$.

\section{TABLE I}

The anthropometric and physiological characteristics of the subjects

\begin{tabular}{|c|c|c|c|c|}
\hline Variable & Mean & SD & & Range \\
\hline Age (years) & 25.8 & 3.4 & 19.0 & -33.0 \\
\hline Height (m) & 1.76 & 0.06 & 1.65 & 1.86 \\
\hline Weight (kg) & 72.3 & 4.6 & 65.2 & -80.8 \\
\hline Percent fat & 11.4 & 1.4 & 8.2 & -16.6 \\
\hline $\mathrm{VO}_{2} \max \left(L \cdot \min ^{-1}\right)$ & 4.68 & 0.46 & 3.75 & 5.38 \\
\hline $\mathrm{VO}_{2} \max \left(\mathrm{ml} \cdot \mathrm{kg}^{-1} \cdot \mathrm{min}^{-1}\right)$ & 65.1 & 4.8 & 59.2 & -76.2 \\
\hline VE ${ }_{S T P D}\left(\right.$ L. $\left.\min ^{-1}\right)$ & 122.3 & 16.8 & 94.4 & -152.3 \\
\hline$H R \max \left(b \cdot \min ^{-1}\right)$ & 190 & 9 & 174 & -209 \\
\hline Run time (s) & 437 & 58 & 402 & -639 \\
\hline
\end{tabular}

The rapid removal of the subjects from the treadmill to a horizontal position resulted in three incidents of ventricular ectopic beats, presumably in response to the rapid drop in cardiac output.

The venous blood lactate concentration increased from $12.65 \pm 0.46 \mathrm{mmol} . \mathrm{L}^{-1}$ at the first minute post exercise to reach a maximum concentration of 14.2 $\pm 0.76 \mathrm{mmol} . \mathrm{L}^{-1}$ at the 6 th $\mathrm{min}$ post exercise (Fig. 1). The net removal of lactate from the venous blood followed a fairly linear decline, reaching a concentration of $7.43 \pm 0.60 \mathrm{mmol} . \mathrm{L}^{-1}$ at the 30 th $\mathrm{min}$. The net rate of lactate removal was calculated from the rectilinear portion of the curve describing changing lactate concentration with respect to time, between the 6 th and 20 th $\min$. The net rate of lactate removal was .30 $\mathrm{mmol} \cdot \mathrm{L}^{-1} \cdot \mathrm{min}^{-1}$.

The results of the analysis of variance with repeated measures, indicated that there were significant differences in the blood lactate concentration from the 1st to the 30th min post exercise. A Newman-Keuls posthoc test indicated that the mean blood lactate concentration from the 4 th, 5th and 6 th $\mathrm{min}$ was significantly different from the blood lactate concentration at the remaining minutes post exercise $(P<0.01)$. There was no significant difference in lactate concentration at the 4 th, 5 th and 6 th $\min$ post exercise $(P>0.05)$. 


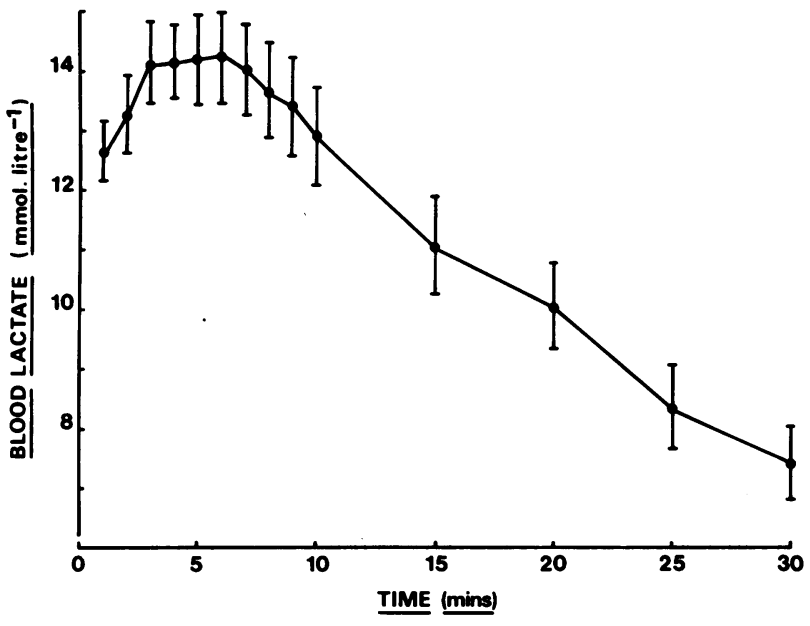

Figure 1: Blood lactate concentration following maximum exercise.

\section{DISCUSSION}

The present study found that the peak post exercise blood lactate concentration occurred at the 6 th $\mathrm{min}$. Statistically there was no significant difference in venous blood lactate concentration between the 4th, 5 th or 6 th $\mathrm{min}$ post exercise. Experience in the initial stages of the present study indicated that the volume of venous blood measured by the gradations on a 5 or 10 $\mathrm{ml}$ syringe may cause changes in venous blood lactate concentration by as much as $10 \%$, leading to a multimodal post exercise venous lactate concentration. In light of this variation in venous lactate concentration, a one $\mathrm{ml}$ pipette was used to pipette all subsequent samples, and the previous samples were discarded. The time at which venous blood lactate reached peak concentration is consistent with the sampling times of Belcastro and Bonen, (1975) who employed a $6 \mathrm{~min}$ cycle ergometer test at approximately $90 \% \mathrm{VO}_{2} \max$, Newman et al, (1936) who exercised subjects at 18.7 $\mathrm{km} \cdot \mathrm{h}^{-1}$ and $12 \%$ grade to exhaustion, Hermansen, (1965) who used successive bouts of maximum intermittent work lasting $60 \mathrm{~s}$, and Johnson and Edwards, (1937) who ran subjects at 14 to $18 \mathrm{~km} \cdot \mathrm{h}^{-1}$ up an $8.6 \%$ grade until exhaustion.

The results of the present study partially confirm the findings of Hermansen and Vaage, (1977) who found that arterial lactate reached peak concentrations one minute post maximum exercise and remained at that level until the 5th min, Davies et al (1970) who exercised the subjects for $6 \mathrm{~min}$ at approximately $80 \%$ $\mathrm{VO}_{2}$ max and sampled venous blood from the 3rd to 6th min post exercise, Margaria et al (1933), Margaria et al (1969) and Karlsson et al (1968) who exercised subjects on either a treadmill, bicycle or cross country run. The present results lend no measure of support to Asmussen (1949) McGrail et al (1978) who reported respective peak lactate concentrations of immediately and one minute post exercise, Hermansen \& Stensvold (1972) Knuttgen (1962) who reported peak lactate concentrations at approximately $2 \mathrm{~min}$ and Diament et al (1968) who noted peak lactate concentrations approximately $10 \mathrm{~min}$ post exercise.

The disparity between the present study and others may be related to several factors: (i) whether the exercise was intermittent or continuous, (ii) the extent of anaerobic metabolism (iii) the method of obtaining a blood sample and subsequent biochemical procedures, (iv) the percentage of slow twitch fibres in the exercising subject and (v) the nature of the recovery following maximum exercise.

While it has been established that lactate removal is enhanced by exercise performed within a given range of percent $\mathrm{VO}_{2}$ max during recovery, (Belcastro and Bonen, 1975; Davies et al, 1970; Hermansen and Stensvold, 1972) and by the percentage of slow twitch fibres (Graham 1978; McGrail et al, 1978) it is by no means established that the time of post exercise peak lactate concentration is dependant upon the mode of exercise.

Notwithstanding certain medical-legal difficulties associated with a venepuncture, the manual finger prick method to obtain a blood sample was discarded because of the uncertainty of obtaining a representative sample of venous blood lactate. The post exercise rate of lactate removal from the venous blood was consistent with values reported by Hermansen and Stensvold (1972) on subjects with an inactive recovery, and Belcastro and Bonen (1975) on subjects who exercised at approximately $30 \%$ of $\mathrm{VO}_{2}$ max during the recovery phase, but slower than removal rates reported by Hermansen and Vaage (1977), on subjects during an inactive recovery period after maximum intermittent exercise.

In conclusion, peak venous blood lactate concentrations occurred at the 6 th $\mathrm{min}$ after progressive exercise to exhaustion lasting on the average $487 \pm 58 \mathrm{~s}$ with an inactive recovery. No significant difference was found between the venous blood lactate concentration between the 4 th, 5 th or 6 th $\mathrm{min}$ post exercise indicating that these post exercise times may be appropriate in runners to sample venous blood for peak lactate concentration.

\section{ACKNOWLEDGEMENT}

This study was supported in part by a grant from Cumberland College of Health Sciences. The authors are grateful to Dr. Jack Jones for his assistance with the medical examinations and venepunctures. 


\section{REFERENCES}

Asmussen, E. 1949 "Pyruvate and lactate content of the blood during and after muscular work". Acta Physiol. Scand. 20: 125-132.

Åstrand, P. O., Hallback, I., Hedman, R. and Saltin, B. 1963 "Blood lactates after prolonged severe exercise". J.Appl. Physiol. 18 (3): 619-622.

Belcastro, A. N. and Bonen, A. 1975 "Lactic acid removal rates during controlled and uncontrolled recovery exercise". J.Appl.Physiol. 39: 932-936.

Davies, C. T. M., Knibbs, A. V. and Musgrove, J. 1970 "The rate of lactic acid removal in relation to different baselines of recovery exercise". Int.Z.Angew.Physiol. 28: 155-161.

Diamant, B., Karlsson, J. and Saltin, B. 1968 "Muscle tissue lactate after maximal exercise in man". Acta Physiol. Scand. 72: 383-384.

Freund, H. and Gendry, P. 1978 "Lactate kinetics after short strenuous exercise in man". Eur.J.Appl.Physiol. 39: 123-135.

George Washington Medical Centre. "Exercise and heart disease project. A collaborative study". A manual of operations, Washington. The Co-ordinating Centre, The George Washington University Medical Centre, 10.1-10.8, 1974.

Graham, T. E. 1978 “Oxygen delivery and blood and muscle lactate changes during muscular activity". Canad.J.Appl. Sport Sci. 3: 153-159.

Hermansen, L. 1965 "Lactate production and removal and the regulation of metabolism". Ann.N.Y.Acad.Sci. 199: 995-1011.

Hermansen, L. and Stensvold, I. 1972 "Production and removal of lactate during exercise in man". Acta Physiol. Scand. 86: 191-201.

Hermansen, L. and Vaage, O. 1977 "Lactate disappearance and glycogen synthesis in human muscle after maximal exercise". Amer.J.Physiol. 233 (5): 422-429.

Johnson, R. E. and Edwards, H. T. 1937 "Lactate and pyruvate in blood and urine after exercise". J.Biol.Chem. 118: 427-432.

Jorfeldt, L., Johlin-Dannfelt, A. and Karlsson, J. 1978 "Lactate release in relation to tissue lactate in human skeletal muscle during exercise". J.Appl.Physiol. 44 (3): 350-352.

Karlsson, J., Diamant, B. and Saltin, B. 1968 "Lactate dehydrogenase activity in muscle after prolonged severe exercise in man". J.Appl.Physiol. 25 (1): 88-91.

Keul, J., Doll, E. and Keppler, D. 1969 "Muskelstoffwechsel”, M̈unchen Barth, 247 pp.

Knuttgen, H. G. 1962 “Oxygen debt, lactate, pyruvate and excess lactate after muscular work". J.Appl.Physiol. 17: 639-644.

Krebs, H. A. 1964 “Gluconeogenesis”. Proc.Roy.Soc.(Lond). 159: 545-565.

Krebs, H. A. and Woodford, M. 1965 “Fructose 1,6 - diphosphatase in striated muscle". Biochem.J. 94: 436-445.

McGrail, J. C., Bonen A. and Belcastro, A. 1978 "Dependance of lactate removal on muscle metabolism in man". Eur.J.Appl.Physiol. 39: 89-97.

Margaria, R., Edwards, H. T. and Dill, D. B. 1933 "The possible mechanisms of contracting and paying the oxygen debt and the role of lactic acid in muscular contraction". Amer.J.Physiol. 114:689-715. 
Margaria, R., Oliva, R. D., DiPrampero and Cerretelli, P. 1969 "Energy utilisation in intermittent exercise of supramaximal intensity". J.Appl.Physiol. 26 (6): 752-756.

Newman, E. V., Dill, D. B., Edwards, H. T. and Webster, F. A. 1937 "The rate of lactic acid removal in exercise". Amer.J.Physiol. 118: 457-462.

Opie, L. H. and Newsholme, E. A. 1967 "The activites of fructose 1,6 diphosphatase, phosphorfructokinase, phosphoenolpyruvate carboxykinase in white and red muscle". Biochem.J. 103: 391-399.

\section{BOOK REVIEW}

Title: “GIVE US THE CHANCE". SPORT AND PHYSICAL RECREATION WITH MENTALLY HANDI. CAPPED PEOPLE

Editor: $\quad$ Kay Latto, DipPE, MCSP

Publisher: $\quad$ The Disabled Living Foundation, 346 Kensington High Street, London W14 8NS. Tel. 01-602-2491, 1981

Price: $\mathbf{£ 9 . 5 0 ~ ( i n c l . ~ P . ~ \& ~ P . ) ~}$

The Disabled Living Foundation over the years has published excellent books containing clear instructions and practical help for those concerned with assisting the handicapped. This publication is superb.

Following two chapters of general advice on the problem written by a consultant psychiatrist, and by a clinical psychologist, the book then deals with teaching points, choice of activity, facilities for games and sport. Following these chapters, the reader is treated to sessions dealing with the development of skill, team involvement, control of movement, agility and perception. The material is very well illustrated by line drawings which tell the story by themselves.

In the 178 pages, the whole range of useful activities is considered and the book concludes with appendices from which additional specialised information might be obtained.

This is a book that should be in the possession of all who deal with the handicapped. It will be found equally useful by the physiotherapist, the physical educationist, and the doctor. The whole tone of the book is a happy, constructive optimism.

Noel Bleasdale 